\title{
Resolution of Three Important $\pi$-Basic Chiral Compounds on Recently Developed Five $\pi$-Acidic Chiral Columns
}

\author{
Jae Jeong Ryoo, Joo-Bo Park, Hae Young Kwon, and Jung Whan Lee

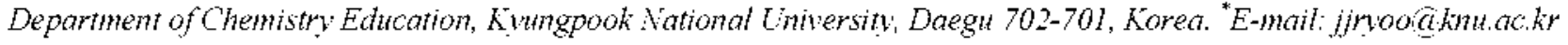 \\ K-HAC, Iuseong, Daejeon 305-380, Korea \\ Received Februarv 21, 2007
}

Key Words : Pirkle-type chiral stationary phases. 1.1'-Bi-2-naphthol, 1.1'-Binaphthỵl-2.2'-diamine. 2.2.2-Trifluoro-1-(9-anthryl)ethanol. Chiral separation

The separation of chiral conpounds is very inportant in various fields, ${ }^{1.2}$ There are many uses for optically pure chiral compounds, ${ }^{3.4}$ for example. chiral catalysts ${ }^{5}$ for asymmetric synthesis, chiral derivatizing agents ${ }^{6}$ for diastereomeric resolution. or good chiral selectors ${ }^{7}$ for direct chiral separation. 1, I'-Bi-2-naphthol (BNO), ${ }^{\mathrm{S}}$ 1.1-binaphthyl-2.2'diamine (BNA), ${ }^{9}$ and 2,2.2-trifluoro-1-(9-antluryl)ethanol (TFAE) ${ }^{1 i}$ are very popular chiral compounds used for the above purposes and their optically pure form are needed and used worldwide. Five Pirkle-type $\pi$-acidic chiral stationary<smiles>CCO[Si](CCCNC(=O)OC[C@H](NC(=O)c1cc([N+](=O)[O-])cc([N+](=O)[O-])c1)c1ccccc1)(OC)O[C@@H]1C[C@H](C)C1(C)C</smiles>

CSP 1<smiles>CCO[Si](CCCNC(=O)OC[C@H](CC(C)C)NC(=O)c1cc([N+](=O)[O-])cc([N+](=O)[O-])c1)(OC)O[C@@H]1C[C@H](C)C1(C)C</smiles>

CSP 2<smiles>CCO[Si]1(CCCNC(=O)OC[C@H](NC(=O)c2cc([N+](=O)[O-])cc([N+](=O)[O-])c2)C(C)(C)C)O[C@H](C)C2CC1C2</smiles><smiles>CC[Si](C)(C)O[Si](CC)(CCCN(C(=O)[C@H](NC(=O)c1cc([N+](=O)[O-])cc([N+](=O)[O-])c1)c1ccccc1)c1ccccc1)OC</smiles>

$\operatorname{csP} 4$<smiles>CCO[Si](CCCN(C(=O)[C@H](CC(C)C)NC(=O)c1cc([N+](=O)[O-])cc([N+](=O)[O-])c1)c1ccccc1)(OC)O[Si](C)(C)C(C)C</smiles>

Figure 1. Chiral stationary phases used in this study.

phases (CSP 1-5. Figure 1) were recently prepared with the testing data of $N$-acyl-1-naphthy laminoalkanes. ${ }^{1,12}$ CSP $1-3$ are aminoalcohol derived CSPs ${ }^{11}$ while CSP 4 and 5 are amino acid derived ones, ${ }^{12}$ however, only a few applications of their use have been reported until now.

In this study, three important chiral compounds, l.l'-bi-2naphthol (BNO). 1, l'-binaphthyl-2,2'-diamine (BNA). 2,2.2trifluoro-1-(9-anthryl)ethanol (TFAE). were used for testing the five Pirkle-type chiral stationary phases. The resolution results were compared to those of commercially available chiral columus.

The chiral separation results of 2,2.2-trifluoro-1-(9-anthryl)ethanol (TFAE) on CSP 1-CSP 5 are shown in Figure 2.

As shown in Figure 2. the enantiomers of TFAE were separated on all five chiral columns, especially, very well resolved on CSP 4. The cluromatographic resolution data of other racemic samples on CSP $1-5$ and commercially available chiral columns are summarized in Table 1

As shown in Table 1. separation of the enantiomers of BNO on CSP 4 and CSP 5 shows similar or better results than that on the commercial Pirkle-type ULMO column, while not on CSP 2 and CSP 3. The enantioners of BNA were separated on all five CSPs, and the best resolution (Rs; 3.41) was shown on CSP 4. The enantioners of TFEA were also separated on all five CSPs and the best resolution (Rs: 6.83) was shown on CSP 4. Even though the number of theoretical plate of the domestic chiral columins (average value calculated from Figure 2; 3.000) being much smaller than that of the famous column (average value calculated from some chromatogrants of 2.2,2-trifluoro-1-(9-anthryl)ethanol provided by a famous columm company; 5,500). ${ }^{13}$ the best resolution on CSP 4 is meaningful.

There are no elution order consistencies in the resolution of the racemic BNO or BNA for any of the CSPS. The " $R$ " isomer of BNO is first eluted on (R)-CSP I while the " $S$ " isomer of BNO is first eluted on (R)-CSP 4 and (S)-CSP 5 The " $R$ " isomer of BNA is first eluted on all CSPs. The reason for the irregular elution order is not known at this time, but it is a topic for further discussion regarding advanced chiral stationary phases. There are elution order consistencies in the resolution of the racemic TFAE on all CSPs. The " $R$ " isomer of TFAE is first eluted on (R)-CSP l and (R)-CSP 4 while the " $\mathrm{S}$ " isomers of TFAE is first eluted 

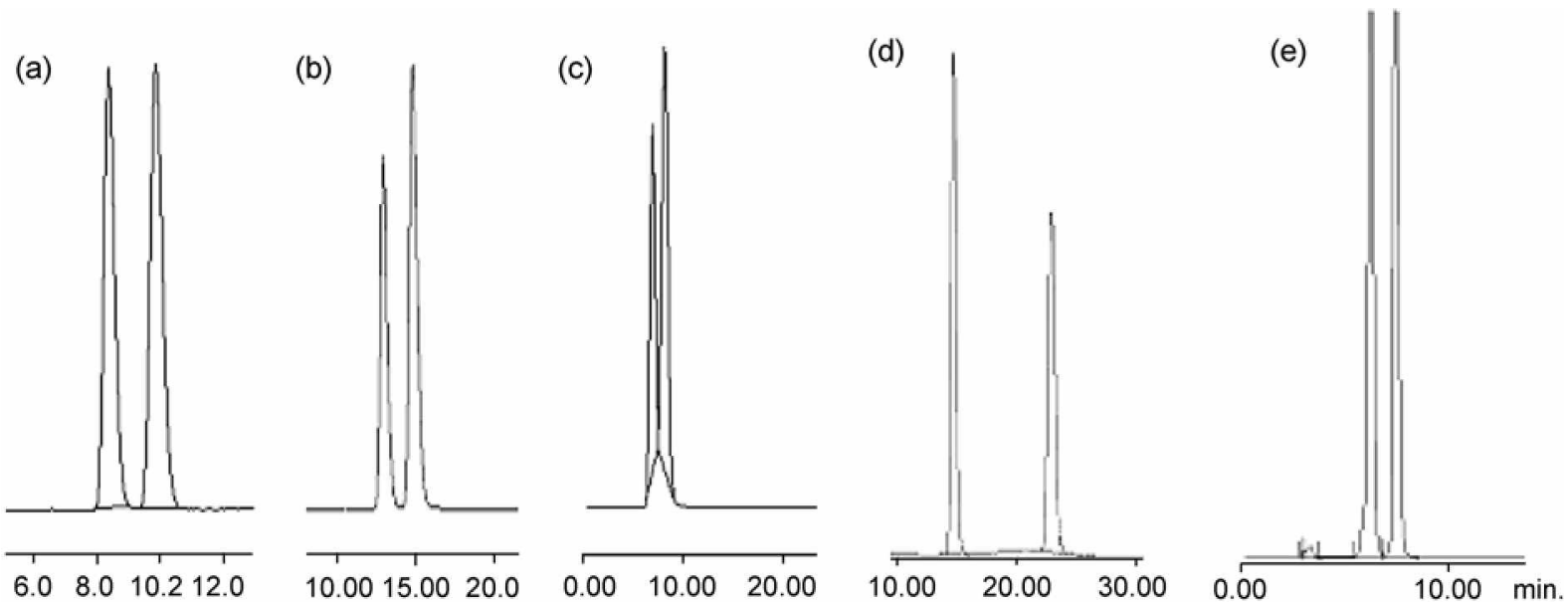

Figure 2. Chiral separation of 2,2,2-trifluoro-1-(9-anthrylethanol on CSP 1(a), CSP 2(b), CSP 3(c), CSP 4(d), and CSP 5(e). Eluent: 10\% IPA/hexane, flow rate: $1.5 \mathrm{~mL} / \mathrm{minm}$, UV $254 \mathrm{~cm}$.

Table 1. Chiral separation of 1,1'-bi-2-naphthol, 1, I'-binaphthyl-2,2'-diamine, and 2,2,2-trifluoro-1-(9-anthryl)ethannol on CSP I-CSP $5^{a}$

\begin{tabular}{|c|c|c|c|c|c|}
\hline Enantiomer & Column & $\begin{array}{l}\text { Flow Rate } \\
(\mathrm{mL} / \mathrm{min})\end{array}$ & $k_{1}(\mathrm{CF}-1)^{b}$ & $\alpha$ & $R_{S}$ \\
\hline \multirow[t]{8}{*}{ 1,1'-Bi-2-11aphthol (BNO) } & (R)-CSP l & 1.5 & $2.26(\mathrm{R})$ & 1.11 & 1.54 \\
\hline & $(\mathrm{S})-\mathrm{CSP} 2$ & 1.5 & 2.77 & 1.00 & 0.00 \\
\hline & (S)-CSP 3 & 1.5 & 2.95 & 1.00 & 0.00 \\
\hline & (R)-CSP 4 & 1.5 & $4.79(\mathrm{~S})$ & 1.27 & 2.62 \\
\hline & (S)-CSP 5 & 1.5 & $3.58(\mathrm{~S})$ & 1.23 & 2.33 \\
\hline & CHIRALPAK OT(+) (DAICEL) & 0.5 & 1.18 & 2.01 & 3.75 \\
\hline & (S,S)-IRMO (REGIS) & 1.0 & 4.84 & 1.24 & 1.91 \\
\hline & Kromasil CHI-DMB, (Kromasil) & 2.0 & 2.06 & 1.99 & 6.33 \\
\hline \multirow{6}{*}{$\begin{array}{l}\text { 1,I'-Binaphthyl-2,2'-diamine } \\
\text { (BNA) }\end{array}$} & (R)-CSP 1 & 1.5 & $6.50(\mathrm{R})$ & 1.15 & 1.54 \\
\hline & (S)-CSP 2 & 1.5 & $15.78(\mathrm{R})$ & 1.14 & 1.61 \\
\hline & (S)-CSP 3 & 1.5 & $6.73(\mathrm{R})$ & 1.16 & 1.36 \\
\hline & (R)-CSP 4 & 1.5 & $6.60(\mathrm{R})$ & 1.31 & 3.41 \\
\hline & (S)-CSP 5 & 1.5 & $2.09(\mathrm{R})$ & 1.19 & 1.86 \\
\hline & CHIRALPAK OT(+)(DAICEL) & 0.5 & 1.67 & 1.39 & 1.08 \\
\hline \multirow{10}{*}{$\begin{array}{l}\text { 2,2,2-Trifluoro-1-(9-anthryl)- } \\
\text { ethanol (TFAE) }\end{array}$} & (R)-CSP 1 & 1.5 & $3.35(\mathrm{R})$ & 1.23 & 1.86 \\
\hline & (S)-CSP 2 & 1.5 & $4.50(\mathrm{~S})$ & 1.18 & 2.00 \\
\hline & (S)-CSP 3 & 1.5 & $2.20(\mathrm{~S})$ & 1.25 & 1.00 \\
\hline & (R)-CSP 4 & 1.5 & $3.24(\mathrm{R})$ & 1.75 & 6.83 \\
\hline & (S)-CSP 5 & 1.5 & $1.12(\mathrm{~S})$ & 1.38 & 2.60 \\
\hline & CHIRALPAK OT(+) (DAICEL) & 0.5 & 0.51 & 1.67 & 1.29 \\
\hline & CHIRALCEL OG (DAICEL) & 0.5 & 1.54 & 1.52 & 3.83 \\
\hline & CHIRALCEL OD (DAICEL) & 0.5 & 2.13 & 2.59 & 6.40 \\
\hline & (R,R)-ULMO $25 \mathrm{~cm} \times 4.6 \mathrm{~mm}(\mathrm{REGIS})$ & 1.0 & 1.36 & 2.02 & 3.71 \\
\hline & CH-TBB. 5 tam $4.6 \times 250 \mathrm{~mm}$ (Kromasil) & 2.0 & 2.04 & 1.17 & 1.29 \\
\hline
\end{tabular}

"Detection: UV $254 \mathrm{~nm}$. Resolution data on commercial columns were achieved from maker's web homepage. "CF-1: Configuration of the first eluted enantioner

on (S)-CSP 2. (S)-CSP 3. and (S)-CSP 5. The reason for this can be explained by classical three point interaction mechanism on chiral discrimination. ${ }^{14}$ It is assumed that there are two attractive interactions and a discriminative steric repulsion interaction between the (R)- and (S)-isomers of TFAE with the five CSPs. A face-to-face $\pi-\pi$ interaction between the anthryl group on the TFAE and the 3,5. dinitrobenzoyl group on the CSPs. and the hydrogen bond- ing interaction between lydroxy group of TFAE and amide group of 3.5-dinitrobenzoylamide on CSPs. can occur in this separation. In addition. a steric repulsion between the hydrogen and trifluoromethyl group of (R)- and (S)-isomers with CSPs can occur as a discriminative interaction.

In a comparison of the enantioseparation results of BNA and TFAE on CSP 1-5 and famous commercial columns. the chiral separation on CSP 4 showed the best resolution even 
though the packing technique of the Korean company (KMAC) was not as good as that of the foreign company. CSP 4 could be useful in a large-scale separation of these three inportant chiral compounds.

\section{Experimental Section}

The HPLC system. consisting of a JASCO (Tokyo, Japan) PU-2080 Plus Intelligent HPLC Pump, a Rheodyne (Cotati. CA. USA) Model 7125 injector with a $20 \mu \mathrm{L}$ sample loop. and a JASCO UV-2075 Plus Lntelligent UV/Vis Detector. were used for HPLC analysis. All chromatographic data were obtained using 10\% 2-propanol in hexane as a mobile phase at a flow rate of $1.5 \mathrm{~mL} / \mathrm{min}$. The columm void volume was checked by injecting 1,3.5-tri-tert-butylbenzene, ${ }^{11}$ which is a presumed unretained solute obtained from the Aldrich Chenical Co. All reagent and test chiral samples used in this study were from the Aldrich Chemical Co. Solvents for $\mathrm{HPLC}$ analysis were purchased from Merck Chemical Co.

Testing samples were prepared by dissolving $5.0 \mathrm{mig}$ of each compound into the $5.0 \mathrm{~mL}$ of methyl alcohol or dichloromethane. The injection volume was $3 \mu \mathrm{L}$. Elution order was checked from optically pure compounds of each enantiomer. The chiral columns used in this study were purchased from KMAC (Daejeon. Korea). ${ }^{15}$ The names of the commercialized colunns were the following: CSP I: CHIRALRYOO PGO-I. CSP 2: CHIRALRYOO LEO-I. CSP 3: CHIRALRYOO TLEO-I, CSP 4: CHIRALHYUN PG-1. CSP 5; CHIRALHYUN LEU-I.

Acknowledgments. This work was supported by Grants from the Korea Research Foundation (KRF-2004-002Cool39).

\section{References}

1. Ward. T. T. Anal Chent 2006. 78. 3947.

2. (a) Pirkle. W. H.: Pochapsky. T. C. Chem. Rev 1989. 89. 347. (b) Hyun. M. H.: Boo. C. T.: Choi. H. T.: Kim. Y. K.: Kang. B. S.: Ha. H. J.: Choi, M. K.; Tan. G. Bull. Korean Chem. Soc. 2007, 28. 363.

3. Kim. Y.: Kang. J. Bull. Kowan Chem. Soc. 2007. 28.363.

4. Marshall. E. Science 1985. 229. 1071.

5. (a) Knowles. F. E. Angew: Chent. Int. Ed 2002. H1. 1998. (b) Sharpless. K. B. Ange't: Chent Int. Ed. 2002. H. 2024. (c) Noyori. R. Angew. Chem. hit. Ed. 2002. 11, 2008.

6. Blazewska, K.; Paneth, P: Gajda. T. J. Org. Chem. 2007. 72(3). 878 .

7. (a) Rizii. S. A. A.: Zheng. J.: Apkarian. R. P.: Dublin. S. N.: Shamsi. S. A. Anal Chent 2007. 79(3). 879. (b) Choi. S.-H.: Noh. H.-T.: Lee. K.-P. Bull. Konean Chent. Soc. 2005. 26. 1549.

8. Hatano, M.: Ikeno. T; Myamoto, T.: Ishihara, K. $J$. Am. Chem Soc. 2005, 127(31). 10776

9. Selby, T. D.: Blackstock. S. C. J. Am. Chem. Soc. 1999, 121(30). 7152 .

10. Fireman-Shoresh. S.: Avnir. D.: Mars. S. Chem. Hater 2003. $15(19) .3607$

11. (a) Ryoo, J. J.: Kim, T. H.; Im, S. H.: Jeong. Y. H: Park. J. Y: Choi. S.-H., Lee, K.-P.: Park. J. H. J. Chromatogr A 2003, 987. 429. (b) Ryoo. J. J.: Song. Y.-A.; Jeong, Y. H. Hyun, M. H.: Park. J. H.: Lee. W. Bull. Korew Chem. Soc. 2006. 27.637.

12. (a) Hyun. M. H.: Na. M. S.: Min. C.-S. J. Chrontatogr: A 1996. 732. 209. (b) Hyun. M. H.: Min1. C.-S. Chralin 1998. 10. 592.

13. http owww daicelchiral com appguide datap 20 : $200-08$. htm

14. Pirkle, W. H.: Murray. P. G.; Wilson, S. R. J. Org. Chem. 1996. $61(14) .4775$

15. http: www.jmac.to: 